\title{
Korean Association for the Study of Intestinal Diseases guidance for clinical practice of adult inflammatory bowel disease during the coronavirus disease 2019 pandemic: expert consensus statements
}

\author{
Yong Eun Park ${ }^{1 *}$, Yoo Jin Lee ${ }^{2 *}$, Ji Young Chang ${ }^{3}$, Hyun Joo Song ${ }^{4}$, Duk Hwan Kim ${ }^{5}$, Young Joo Yang ${ }^{6}$, \\ Byung Chang Kim ${ }^{7}$, Jae Gon Lee ${ }^{8}$, Hee Chan Yang ${ }^{9}$, Miyoung Choi ${ }^{10}$, Seong-Eun Kim ${ }^{11}$, Seung-Jae Myung ${ }^{12}$ \\ ${ }^{1}$ Division of Gastroenterology, Department of Internal Medicine, Haeundae Paik Hospital, Inje University College of Medicine, Busan; ${ }^{2}$ Division \\ of Gastroenterology and Hepatology, Department of Internal Medicine, Keimyung University School of Medicine, Daegu; ${ }^{3}$ Health Promotion \\ Center, Ewha Womans University Seoul Hospital, Seoul; ${ }^{4}$ Department of Internal Medicine, Jeju National University College of Medicine, Jeju; \\ ${ }^{5}$ Digestive Disease Center, CHA Bundang Medical Center, CHA University, Seongnam; ${ }^{6}$ Department of Internal Medicine, Hallym University \\ College of Medicine, Chuncheon; ${ }^{7}$ Center for Colorectal Cancer, National Cancer Center, Goyang; ${ }^{8}$ Department of Internal Medicine, Hallym \\ University Dongtan Sacred Heart Hospital, Hallym University College of Medicine, Hwaseong; ${ }^{9}$ Division of Gastroenterology and Hepatology \\ Department of Internal Medicine, Jeonbuk National University Medical School, Jeonju; ${ }^{10}$ Division of Healthcare Technology Assessment \\ Research, National Evidence-based Healthcare Collaborating Agency, Seoul; ${ }^{11}$ Department of Internal Medicine, Ewha Womans University \\ College of Medicine, Seoul; ${ }^{12}$ Department of Gastroenterology, Asan Medical Center, University of Ulsan College of Medicine, Seoul, Korea
}

Many unexpected problems have resulted from the unprecedented coronavirus disease 2019 (COVID-19) pandemic. The optimal management of patients with inflammatory bowel disease (IBD) during the COVID-19 pandemic has also been a challenge. Therefore, the Korean Association for the Study of Intestinal Diseases (KASID) developed a consensus statement of experts regarding the management of IBD during the COVID-19 pandemic. This consensus statement made recommendations regarding the risk and treatment of COVID-19 in IBD patients. This statement emphasizes that IBD is not a risk factor for COVID-19, and care should be taken not to exacerbate IBD in patients in remission state by maintaining their medications, except for corticosteroids. (Intest Res 2022;20:431-444)

Key Words: SARS-CoV-2; COVID-19; Inflammatory bowel disease; Management

Received August 8, 2021. Revised September 7, 2021

Accepted September 9, 2021

Correspondence to Seong-Eun Kim, Department of Internal Medicine, Ewha Womans University College of Medicine, 1071 Anyangcheon-ro, Yangcheongu, Seoul 07985, Korea. Tel: +82-2-2650-2845, Fax: +82-2-2655-2076, E-mail: kimse@ewha.ac.kr

Co-Correspondence to Seung-Jae Myung, Department of Gastroenterology, Asan Medical Center, University of Ulsan College of Medicine, 88 Olympic-ro 43-gil, Songpa-gu, Seoul 05505, Korea. Tel: +82-2-3010-3917, Fax: +82-2-

476-0824,E-mail: sjmyung@amc.seoul.kr

*These authors contributed equally to this study.

This guideline is being co-published in Intestinal Research (in English) and the Korean Journal of Gastroenterology (in Korean) for the facilitated distribution.

\section{INTRODUCTION}

In 2019, the coronavirus, first identified in Wuhan, China, in 2019 was named severe acute respiratory syndrome coronavirus-2 (SARS-CoV-2) by the International Committee on Taxonomy of Viruses (ICTV) and the World Health Organization (WHO). The disease caused by SARS-CoV-2 infection was defined as coronavirus disease 2019 (COVID-19)., ${ }^{1,2}$ COVID-19 has various manifestations, from asymptomatic to severe clinical symptoms. The main symptoms are fever, cough, loss of smell and taste, and fatigue. Less common symptoms include 
sore throat, muscle pain, chills, headache, and gastrointestinal symptoms such as nausea, vomiting, and diarrhea. ${ }^{3,4}$ The infection spread rapidly around the world, and the COVID-19 pandemic was declared by the WHO in March 2020. Although there are differences between countries and regions, COVID-19 has higher hospitalization and mortality than expected and higher transmissibility rates compared to those for previously reported coronavirus diseases by SARS-CoV and Middle East respiratory syndrome (MERS)-CoV. ${ }^{1}$ Among COVID-19 patients, those with chronic underlying diseases are more likely to progress to serious disease. Therefore, there is concern about the risk of COVID-19 and its treatment in patients with inflammatory bowel disease (IBD), a chronic immune-mediated intestinal disease commonly treated with immunosuppressants.

Accordingly, the Korean Association for the Study of Intestinal Diseases (KASID) has drawn up an expert consensus statement on clinical practice for IBD patients during the COVID-19 pandemic. Because evidence is lacking, the clinical data available to date, as well as the international recommendations of expert groups or academic societies, were reviewed to generate a consensus of Korean IBD clinical experts using the modified Delphi method. ${ }^{5,6}$ A 9-point Likert scale questionnaire was provided by e-mail together with supporting data. Any questionnaire statement with a coefficient of variation of $<0.5$ was adopted as a recommendation. Forty domestic IBD clinical experts participated in the consensus process, and the 10 consensus statements met the coefficient of variation criterion in the first round. Additionally, any reasonable minority opinion was leveraged to revise the corresponding statement via internal discussion in the development working group, and the revised statements were agreed with the participating experts (Table 1). As more information on COVID-19 becomes available, the consensus statements may be revised. It is hoped that this guidance will improve the quality of treatment for IBD patients and facilitate communication between physicians.

\section{RISKS}

\section{Is there an increased risk of developing SARS-CoV-2 infection or COVID-19 in IBD patients?}

\section{Statement 1}

In patients with IBD, the disease itself does not increase the risk of developing SARS-CoV-2 infection or COVID-19.

IBD is a chronic inflammatory immune-mediated intestinal disease comprising Crohn's disease and ulcerative colitis and requires long-term treatment. ${ }^{7-9}$ IBD patients, particularly those on immunosuppressive agents, may be at increased risk of viral infection. ${ }^{10-12}$ However, there is insufficient evidence on the risk of an increased incidence of SARS-CoV-2 or COVID-19 in IBD patients.

A Danish population-based cohort study found that $3.7 \%$ of 2.6 million patients were SARS-CoV-2 positive. The infection rate was significantly lower (2.5\%) among those with IBD. ${ }^{13}$ In a cohort of 34,763 IBD patients in Germany, COVID-19 occurred in 100 patients $(0.29 \%), 20 \%$ of whom had severe disease. The risk factors for severe COVID-19 were $>65$ years of age and at least 1 underlying comorbidity. However, there was no significant difference in the incidence of COVID-19 between the overall population and patients with IBD. ${ }^{14}$ A metaanalysis of 9,177 IBD patients in 6 studies reported a COVID-19 incidence in IBD patients of about $0.3 \%$, similar to that in the general population $(0.2 \%-4.0 \%){ }^{15}$

The overall risk of developing severe COVID-19 in IBD patients infected with SARS-CoV-2 was similar to that in nonIBD patients infected with SARS-CoV-2. In a large cohort study in the United States, the rates of severe COVID-19 and hospitalization among 232 IBD patients confirmed with COVID-19 was similar to that among 19,776 non-IBD patients with COVID-19. ${ }^{16}$ A case-control cohort study in New York also did not show a higher incidence of severe COVID-19 in patients with IBD compared to matched non-IBD patients. ${ }^{17}$ Intensive care unit (ICU) admission rates, mortality rates, and mechanical ventilation rates were lower in IBD patients than in matched controls. ${ }^{17}$ The severity of clinical symptoms of COVID-19 in IBD patients was milder than in controls. ${ }^{18-22}$ Although IBD is an immune-mediated intestinal disease, other risk factorssuch as old age, heart disease, diabetes, and high blood pressure-are associated with severe COVID-19 rather than IBD itself. $^{23-27}$

Angiotensin converting enzyme II (ACE2) acts as a receptor for the spike protein on the SARS-CoV-2 surface, resulting in internalization of the virus. ${ }^{28}$ ACE2 is expressed by lung alveolar cells and small intestinal epithelial cells, so COVID-19 may lead to gastrointestinal symptoms. ${ }^{29,30}$ ACE2 expression is low in IBD patients and immunosuppressant or biologic treatment may reduce it further, resulting in a low prevalence of COVID-19, but evidence is lacking. ${ }^{15,31,32}$

Based on the above evidence, the American Gastroenterological Association (AGA) promulgated an expert commentary stating that IBD patients are not at greater risk of SARS- 
Table 1. Consensus Statements on Clinical Practice of Adult IBD during the COVID-19 Pandemic by KASID

\begin{tabular}{|c|c|c|c|}
\hline Accepted statements & $\begin{array}{l}\text { Strength of } \\
\text { agreement } \\
\text { (mean) }\end{array}$ & SD & $\mathrm{CV}$ \\
\hline $\begin{array}{l}\text { 2. Although the risk of many infectious diseases in patients with moderate to severe IBD is increased, } \\
\text { the evidence of increased risk of SARS-CoV-2 infection is insufficient. However, there is an elevated } \\
\text { risk of severe pneumonia and mortality due to COVID-19 in older adults, patients with underlying } \\
\text { comorbidities, or patients with active disease. }\end{array}$ & 7.9 & 0.86 & 0.11 \\
\hline $\begin{array}{l}\text { 3. There is insufficient evidence that intestinal symptoms are exacerbated by COVID-19 in IBD patients. } \\
\text { If gastrointestinal symptoms worsen in SARS-CoV-2-infected IBD patients, careful observation is } \\
\text { necessary because the symptoms may have been caused by worsening of IBD itself. }\end{array}$ & 7.9 & 0.66 & 0.08 \\
\hline $\begin{array}{l}\text { 4. It is recommended to maintain the treatment regimen in IBD patients in remission and not infected } \\
\text { with SARS-CoV-2, even in COVID-19-endemic areas. }\end{array}$ & 8.6 & 0.67 & 0.08 \\
\hline $\begin{array}{l}\text { 6. As in the general population, IBD patients are advised to follow personal hygiene practices and } \\
\text { public health recommendations, such as washing hands, wearing a mask, and social distancing. }\end{array}$ & 8.8 & 0.55 & 0.06 \\
\hline $\begin{array}{l}\text { 7-1. For patients with newly diagnosed or exacerbated IBD, testing to rule out COVID-19 should be } \\
\text { considered if the symptoms cannot be differentiated from those of COVID-19. }\end{array}$ & 8.0 & 0.90 & 0.11 \\
\hline $\begin{array}{l}\text { 7-2. Patients with newly diagnosed or exacerbated IBD should follow the IBD treatment guidelines } \\
\text { recommended before the COVID-19 pandemic. }\end{array}$ & 8.4 & 0.74 & 0.09 \\
\hline $\begin{array}{l}\text { 8. There is no need to switch from intravenous biologics to oral administration or subcutaneous } \\
\text { injections to reduce the number of hospital visits for IBD patients. Patients should follow personal } \\
\text { hygiene and quarantine guidelines and maintain regular intravenous biologic treatments. }\end{array}$ & 8.3 & 0.74 & 0.09 \\
\hline $\begin{array}{l}\text { 9-1. Pregnant IBD patients should be considered at high risk of COVID-19, but treatment should not be } \\
\text { changed for those in remission and not infected with SARS CoV-2. }\end{array}$ & 8.6 & 0.55 & 0.06 \\
\hline
\end{tabular}

The response scale is a 9-Likert scale, ranging from 1 point (strongly disagree) to 9 points (strongly agree), and the closer to 9, the higher strength of agreement; $\mathrm{CV}=\mathrm{SD} /$ mean.

IBD, inflammatory bowel disease; COVID-19, coronavirus disease 2019; KASID, Korean Association for the Study of Intestinal Diseases; SD, standard deviation; CV, coefficient of variation; SARS-CoV-2, severe acute respiratory syndrome coronavirus-2; 5-ASA, 5-aminosalicylic acid.

CoV-2 infection or COVID- $19,{ }^{33}$ consistent with recommendations from the British Society of Gastroenterology (BSG) ${ }^{34}$ and Gastroenterological Society of Australia. ${ }^{35}$

Therefore, based on clinical data, the risk of COVID-19 in patients with IBD in remission is not increased compared to the general population. However, if active inflammation is not controlled due to worsening of IBD disease, the risk of severe infection may generally increase and immunosuppressives may be needed, so careful management is required to maintain IBD remission (refer to statement 2 for details).

\section{Is there an increased risk of SARS-CoV-2 infection in IBD patients with moderate to severe disease activity?}

\section{Statement 2}

Although the risk of many infectious diseases in patients with moderate to severe IBD is increased, the evidence of increased risk of SARS-CoV-2 infection is insufficient. However, there is an elevated risk of severe pneumonia and mortality due to COVID-19 in older adults, patients with underlying comorbidities, or patients with active disease.

There is insufficient evidence on the risk of SARS-CoV-2 infec- 
tion according to disease activity in IBD patients. Reports to date have mainly compared the rates of severe pneumonia and hospitalization between the IBD patient group and the non-IBD patient group affected by COVID-19. The risk of severe COVID-19 is not increased by IBD in terms of the rates of severe pneumonia and hospitalization. ${ }^{16,36}$ However, an Italian study of 79 IBD patients with COVID-19 reported that the risk of severe pneumonia and mortality was higher in older patients, patients with comorbidities such as hypertension and cardiovascular diseases, and those with active IBD. ${ }^{3}$

According to the Australian recommendations, ${ }^{35}$ although IBD patients with moderate to severe disease activity are at increased risk of opportunistic infections, ${ }^{37}$ evidence on the risk of COVID-19 is insufficient. However, active disease could increase susceptibility to COVID-19 as a result of systemic steroid use and hospitalization, so effective IBD management is vital. Therefore, it is important for IBD patients to comply with recommendations on diet, smoking, alcohol, and medications to prevent worsening of the disease, and to inform their physician if symptoms worsen.

\section{Does SARS-CoV-2 infection affect gastrointestinal symptoms in IBD patients?}

\section{Statement 3}

There is insufficient evidence that intestinal symptoms are exacerbated by COVID-19 in IBD patients. If gastrointestinal symptoms worsen in SARS-CoV-2-infected IBD patients, careful observation is necessary because the symptoms may have been caused by worsening of IBD itself.

The typical symptoms of COVID-19 infection are sore throat, fever, cough, dyspnea, myalgias, fatigue, headache, and loss of smell or taste, ${ }^{3,4}$ but gastrointestinal symptoms can also appear occasionally. ${ }^{38}$ In COVID-19 case reports and retrospective studies, the rate of gastrointestinal symptoms varied from $3-79 \%$ and included anorexia (39.9\%-50.2\%), diarrhea (2.0\%$49.5 \%)$, vomiting (3.6\%-66.7\%), nausea (1.0\%-29.4\%), abdominal pain (2.2\%-6.0\%), and gastrointestinal bleeding (4.0\%$13.7 \%) .^{39}$ In the United States, $61.3 \%$ of COVID-19 patients had 1 or more gastrointestinal symptoms, $20.3 \%$ had gastrointestinal issues as the major symptom, and $14.2 \%$ complained of gastrointestinal issues as the initial symptom. ${ }^{40}$ In patients with COVID-19, the duration of diarrhea was 1-14 days (average duration, $5.4 \pm 3.1$ days) and the daily frequency of bowel movements was $4.3 \pm 2.2 .^{41-43}$ Gastrointestinal symptoms can be caused by SARS-CoV-2 because its receptor, ACE2, is expressed in the intestinal mucosa. ${ }^{30,44,45}$ Viral RNA was detected in the feces of up to $50 \%$ of patients with mild COVID-19 symptoms and remained detectable in the feces of more than $20 \%$ of infected patients after respiratory viral RNA became negative. $^{46}$

Because gastrointestinal issues such as diarrhea and abdominal pain are the principal symptoms of IBD, it may be difficult to determine whether these symptoms are due to SARS-CoV-2 infection or exacerbation of IBD. In a meta-analysis of 7 studies of 1,325 IBD patients with COVID- $19,{ }^{38}$ the clinical symptoms were fever (67.53\%), cough (59.58\%), diarrhea (27.26\%), rhinorrhea (27\%), and dyspnea (25.29\%).

In Surveillance Epidemiology of Coronavirus Under Research Exclusion (SECURE-IBD), an international COVID-19 registry database for IBD patients, nausea, vomiting, and abdominal pain were significantly more frequent in IBD patients than in non-IBD patients. However, there was no significant difference between the 2 groups in laboratory findings. ${ }^{16}$ There is no evidence of a correlation between specific clinical symptoms in IBD patients confirmed to have COVID-19 and laboratory abnormalities such as inflammatory markers. Careful observation is necessary because worsening of the gastrointestinal symptoms of IBD patients with COVID-19 may be caused by exacerbation of IBD.

\section{MANAGEMENT OF IBD}

\section{Should the long-term maintenance treatment regimen for IBD be altered because of concerns about SARS-CoV-2 infection during the COVID-19 pandemic?}

\section{Statement 4}

It is recommended to maintain the treatment regimen in IBD patients in remission and not infected with SARSCoV-2, even in COVID-19-endemic areas.

Because a large number of patients with IBD receive immunomodulatory therapy, a question has been raised over whether therapeutic agents for IBD increase the risk of SARSCoV-2 infection. Theoretically, immune-system dysfunction could increase the risk of opportunistic viral infections ${ }^{47}$ and decrease viral clearance. Alternatively, immunosuppression could reduce the risk of the cytokine storm associated with adult respiratory distress syndrome. ${ }^{48}$

Several clinical studies have reported that patients on im- 
munomodulatory therapy do not have a higher risk of SARSCoV-2 infection or severe COVID-19 than the general population. Most SARS-CoV-2 infections are asymptomatic or mild in many immunocompromised individuals, including children receiving chemotherapy, ${ }^{49}$ transplanted patients, ${ }^{50,51}$ and patients with HIV (human immunodeficiency virus) infection and/or AIDS (acquired immunodeficiency syndrome). ${ }^{52}$ A Chinese study of 1,099 patients with COVID-19 detected only 2 immunocompromised patients, who did not progress to serious illness. ${ }^{23}$

According to the SECURE-IBD extended follow-up report, which analyzed 1,439 IBD patients with COVID-19 from 47 countries, patients who received thiopurine monotherapy or combination therapy with thiopurine and anti-tumor necrosis factor (TNF) agents were approximately 4 -fold more likely to develop severe COVID-19 than those who received anti-TNF monotherapy. In addition, there was a 1.7 -fold higher risk of severe COVID-19 in patients with IBD who received mesalamine/sulfasalazine than in those who did not. By contrast, anti-TNF agents, anti-interleukin 12/23 agents (ustekinumab), and integrin antagonists (vedolizumab) were not associated with an increased risk of severe COVID-19. ${ }^{53}$ Analysis of the SECURE-IBD cohort data did not find an association between use of tofacitinib and increased risks of hospitalization, ICU admission, and severe COVID-19. ${ }^{54}$

Given the clinical data available to date, the relationship between IBD treatment and severe COVID-19 infection remains unclear. The BSG guidelines stratify the risk of severe COVID-19 for patients with IBD into high-risk, moderate-risk, and low-risk groups according to clinical characteristics. ${ }^{34}$ The high-risk group comprises IBD patients with comorbidities such as pulmonary diseases, heart diseases, hypertension, and diabetes; patients over 70 years of age; patients with moderate to severely active disease not controlled by "moderate risk" treatments; patients receiving intravenous or oral prednisolone $20 \mathrm{mg}$ /day or more; patients who started treatment with biologic plus immunomodulator or systemic steroids within previous 6 weeks; patients with short bowel syndrome; and patients requiring intravenous nutritional support. For the high-risk group, the guidelines do not recommend discontinuation or change of treatment regimen for IBD but, instead, recommend self-isolation from the general population ("shielding"). The moderate-risk group comprises patients receiving anti-TNF monotherapy, stable patients receiving combination therapy with biologic and immunomodulator, and patients receiving ustekinumab, vedolizumab, thiopurines, methotrexate, calcineurin inhibitors, Janus kinase inhibitors (tofacitinib), mycophenolate mofetil, thalidomide, and prednisolone $<20$ $\mathrm{mg} /$ day, for whom stringent social distancing was recommended rather than stopping or changing treatment regimens. The low-risk group comprises patients on 5-aminosalicylic acid (5-ASA), local agents for rectal therapy, budesonide or beclomethasone, antidiarrheals, or antibiotics, for whom social distancing was recommended.

A common recommendation in many countries is that medical treatment for IBD should not be discontinued. ${ }^{33-35,48}$ According to the guidelines of the AGA, patients with IBD should continue their IBD therapies to maintain remission, and care should be taken to prevent disease recurrence due to discontinuation of IBD therapies. This is because if a patient arbitrarily discontinues IBD medication due to concerns about COVID-19 and IBD subsequently flares, the patient may need systemic steroids or hospitalization, and may have a poor clinical course. Strict social distancing, working at home, meticulous hand hygiene, and isolation from infected persons are important for preventing SARS-CoV-2 infection among patients with IBD, as in the general population. ${ }^{33,55}$ It is unclear whether the risk of severe COVID-19 is increased by IBD treatment regimens, but IBD medications should be maintained if the disease is in remission, even in SARS-CoV-2 endemic areas.

\section{Is the use of corticosteroids safe in IBD patients during the COVID-19 pandemic?}

\section{Statement 5}

In IBD patients who are asymptomatic or have improved, without SARS-CoV-2 infection, it is recommended that corticosteroids be reduced as soon as possible. However, the decision should take into consideration IBD disease activity and COVID-19 prevalence.

Systemic steroid use is associated with increased morbidity and mortality in respiratory infections and various viral infections, including influenza, SARS-CoV, and MERS-CoV. ${ }^{48,56}$ On the other hand, because SARS-CoV, MERS-CoV, and SARS$\mathrm{CoV}-2$ trigger production of large amounts of cytokines, steroids had been used for patients with severe disease, with the aim of reducing inflammation-induced lung damage. However, steroid administration delayed viral clearance rather than alleviating inflammation in SARS and MERS, and the evidence for steroid treatment is poor. ${ }^{57-59}$ The WHO interim guidance 
recommends against routinely administering corticosteroids for COVID-19. ${ }^{60}$

A New York matched cohort study that enrolled 80 IBD patients and 160 non-IBD patients with COVID-19 found that IBD did not increase the risk of COVID-19, but moderate to severe active disease and chronic steroid users has a high incidence of COVID-19. However, that study was limited by the small number of patients with active disease and steroid use. ${ }^{17}$ Another U.S. multicenter study reported an increased risk of severe COVID-19 in IBD patients who received corticosteroids within 3 months before diagnosis of COVID-19 (30.98\%) compared to those who did not (19.25\%) (unadjusted analysis: relative risk, 1.60; 95\% confidence interval [CI], 1.01-2.57; $P=0.04){ }^{16}$

Risk factors for severe COVID-19 were investigated in 525 IBD patients with COVID-19 in 33 countries using SECUREIBD. Thirty-seven patients (7\%) progressed to severe disease, and old age, 2 or more comorbid underlying diseases, and systemic corticosteroid use were identified as risk factors. ${ }^{18} \mathrm{Be}$ cause high-dose corticosteroids increase the risk of respiratory and opportunistic infections in IBD patients, ${ }^{61,62}$ the BSG guidelines recommend rapid dose reduction $(10 \mathrm{mg} / \mathrm{wk})$ if possible. $^{34}$ The Asian Pacific Association of Gastroenterology (APAGE) recommends that dose reduction be considered in patients on prednisolone $>20 \mathrm{mg}$ per day, depending on disease activity. Topical treatment or budesonide is recommended as an alternative. $^{63}$

Therefore, if an asymptomatic or clinically improving IBD patient without SARS-CoV-2 infection in a SARS-CoV-2 endemic area is on high-dose systemic corticosteroids (prednisolone $\geq 20 \mathrm{mg} /$ day), corticosteroids should be reduced as soon as possible. The decision should be made considering the clinical condition of the patient (Table 2).

\section{Are there differences in prevention guidelines for IBD patients in the COVID-19 pandemic era?}

\section{Statement 6}

As in the general population, IBD patients are advised to follow personal hygiene practices and public health recommendations, such as washing hands, wearing a mask, and social distancing.

All IBD patients should follow the same prevention guidelines as the general population to reduce the risk of SARS-CoV-2 infection, such as washing hands, wearing a mask, and social distancing. ${ }^{64}$ Smoking cessation is recommended because smoking can cause severe COVID-19 and increase IBD activity. ${ }^{35}$ If possible, telecommuting (or working at home) is recommended and travel and frequent contact with others should be avoided. If an IBD patient has persistent cough, cold symptoms, fever, or rapidly deteriorating gastrointestinal symptoms, they should be tested for SARS-CoV-2 infection according to government guidelines. Although the BSG guidelines classified the risk level of IBD patients and recommend very strict isolation for those at high risk, ${ }^{34}$ most guidelines, including this statement, advise patients to comply with standard prevention policies for the general population for convenience. However, because the clinical situation differs among patients, it may be necessary for medical staff to counsel patients on COVID-19 risk and prevention according to the therapeutic agent(s) used (refer to statement 4 for details).

Table 2. Recommended Therapeutics for SARS-CoV-2-Negative Inflammatory Bowel Disease Patients in Clinical Remission or Improvement during the COVID-19 Pandemic

\begin{tabular}{ll}
\hline \multicolumn{1}{c}{ Medication } & \multicolumn{1}{c}{ Recommendation } \\
\hline 5-ASA & Maintain \\
Budesonide & Maintain \\
Corticosteroids & Reduce if possible (do not exceed prednisolone 20 mg/day, and rapid reduction is recommended) \\
Immunomodulators (thiopurine/methotrexate) & Maintain \\
Anti-TNF (infliximab, adalimumab, golimumab) & Maintain, avoid drug changes if possible in stable patients \\
Vedolizumab & Maintain \\
Ustekinumab & Maintain \\
Tofacitinib & Maintain \\
\hline
\end{tabular}

SARS-CoV-2, severe acute respiratory syndrome coronavirus-2; COVID-19, coronavirus disease 2019; 5-ASA, 5-aminosalicylic acid; TNF, tumor necrosis factor. 


\section{Is the treatment of IBD patients newly diagnosed with IBD or suddenly worsening during the COVID-19 pandemic different from the standard guidance, as before the COVID-19 pandemic?}

\section{Statement 7-1}

For patients with newly diagnosed or exacerbated IBD, testing to rule out COVID-19 should be considered if the symptoms cannot be differentiated from those of COVID-19.

\section{Statement 7-2}

Patients with newly diagnosed or exacerbated IBD should follow the IBD treatment guidelines recommended before the COVID-19 pandemic.

Although there is little evidence that SARS-CoV-2 worsens IBD, COVID-19 can cause diarrhea and abdominal pain, so it is sometimes difficult to distinguish whether a patient has worsening of IBD symptoms or symptoms of COVID-19. The European Crohn's and Colitis Organisation (ECCO) guidelines therefore recommend that IBD patients should be screened to rule out SARS-CoV-2 infection if their intestinal symptoms worsen. ${ }^{48,65}$ In a recent ECCO survey of clinicians, ${ }^{66}$ approximately $75 \%$ of respondents stated that COVID-19 testing was not necessary in patients with asymptomatic IBD, and $62.8 \%$ stated that asymptomatic IBD patients on immunomodulatory treatment do not need a SARS-CoV-2 test. However, $54.6 \%$ of respondents stated that SARS-CoV-2 is necessary for IBD patients with symptoms suspicious for COVID-19. Because viral shedding is maximal in early SARS-CoV-2 infection, and the virus can be transmitted by asymptomatic patients, if IBD patients who visit hospital frequently have a myalgia, sputum, diarrhea, loss of smell or taste, or a history of contact with an infected person, they should be tested immediately, and protective measures implemented.

To date, studies on the influence of new drug administration in IBD patients with newly diagnosed or exacerbated diseases are lacking. The ECCO-COVID Task Force recommends that active IBD be treated according to standard guidelines, as before the COVID-19 pandemic. ${ }^{48}$ Therefore, SARSCoV-2 infection should be excluded in IBD patients with worsened intestinal symptoms that are difficult to differentiate from COVID-19-related symptoms. Standard treatment guidelines should be followed if these patients do not have COVID-19 infection. However, the choice of drug should consider the prevalence of COVID-19, whether the patient is infected, and their IBD activity.

\section{During the COVID-19 pandemic, should IBD patients on maintenance treatment with intravenous biologics change their medications to reduce the number of hospital visits?}

\section{Statement 8}

There is no need to switch from intravenous biologics to oral administration or subcutaneous injections to reduce the number of hospital visits for IBD patients. Patients should follow personal hygiene and quarantine guidelines and maintain regular intravenous biologic treatments.

Concern has been raised about frequent hospital visits during the COVID-19 pandemic for patients with IBD receiving routine intravenous therapy (e.g., infliximab, ustekinumab, and vedolizumab). An International Organization for the Study of Inflammatory Bowel Disease (IOIBD) consensus recommended that regular visits to hospital for intravenous treatment be continued on the condition that COVID-19 screening protocols or quarantine guidelines are followed. ${ }^{33,67}$ Protocols or quarantine guidelines should include prescreening for $\mathrm{CO}$ VID-19 exposure and symptoms, fever screening, maintaining a minimum distance of $2 \mathrm{~m}$, hand sanitizer, and provision of masks and gloves at the hospital entrance. ${ }^{33,67}$ Elective switching from infliximab to adalimumab is associated with intolerance and loss of efficacy within 1 year. ${ }^{68}$ This is a reason for not electively switching intravenous infliximab infusion to subcutaneous adalimumab injection to reduce the number of hospital visits during the COVID-19 era.

The ECCO guidelines ${ }^{48}$ advise telemedicine or remote monitoring for IBD patients unable to visit a hospital. There were several studies on telemedicine before the COVID-19 era. These involved a specific symptom questionnaire and stool calprotectin test at home and counseling by telephone. In those studies, telemedicine was as safe as conventional followup for IBD patients. ${ }^{48,69,70}$ Telemedicine has been temporarily permitted in South Korea during the COVID-19 pandemic to reduce the number of unnecessary appointments.

In Korea, hospitals comply with quarantine guidelines including fever screening and an interview before admission, social distance, hand sanitizing, and wearing a mask, which enable safe injection therapy. However, if the symptoms of an IBD patient who attends hospital for injection treatment cannot rule out COVID-19, the patient should be tested for SARSCoV-2 infection before their appointment and consult with medical staff. 


\section{MANAGEMENT OF PREGNANT IBD PATIENTS DURING THE COVID-19 PANDEMIC}

\section{What are the guidelines for pregnant IBD patients during the COVID-19 pandemic?}

\section{Statement 9-1}

Pregnant IBD patients should be considered at high risk of COVID-19, but treatment should not be changed for those in remission and not infected with SARS-CoV-2.

\section{Statement 9-2}

If a pregnant IBD patient is confirmed to have COVID-19, 5-ASA can be maintained, but thiopurine and corticosteroids should be discontinued or reduced depending on disease activity.

Although not immunosuppressed, women in pregnancy are more vulnerable to viral infection due to a reduced cell-mediated immune response. ${ }^{71}$ Also, pregnancy is associated with increased severity of respiratory illnesses, such as SARS, MERS, and influenza. ${ }^{72-75}$ Therefore, pregnant IBD patients should be considered at high risk of developing severe COVID-19. Although evidence is sparse, the rate of ICU admission of COVID-19-positive women in pregnancy or postpartum was higher compared to women of the same age group in a recent Swedish study. ${ }^{76}$ Moreover, spontaneous abortion was reported in a COVID-19-positive woman with severe active ulcerative colitis in the first trimester. ${ }^{77}$ Therefore, strict personal protective measures such as hand hygiene and social distancing are vital for pregnant IBD patients and their family. If a family member is confirmed to have COVID-19, pregnant women with IBD should be tested for COVID-19 immediately and inform their attending physician as soon as possible.

There is an increased risk of venous thromboembolic events in pregnant and postpartum women. ${ }^{78}$ Because the risk of venous thromboembolism is high in patients with IBD and those with severe COVID-19, the ECCO guidelines recommend that all hospitalized pregnant women with IBD receive anticoagulant prophylaxis. ${ }^{79}$

Despite a dearth of data, the ECCO guidelines suggest that pregnant women with IBD in a stable state be treated identically as before the pandemic if not infected with SARS-CoV-2. ${ }^{79}$ However, in pregnant patients with new-onset IBD or a relapse of IBD during the COVID-19 pandemic, it is recommended to avoid corticosteroids if possible and not to start thiopurine. Cyclosporine or an anti-TNF agent may be considered as an alternative treatment for active IBD in this situation, but the decision should consider the patient's condition, such as disease location and severity.

If pregnant IBD patients diagnosed with COVID-19 are in remission, discontinuation of all IBD medications except 5-ASA and close monitoring is recommended. If a pregnant IBD patient diagnosed with COVID-19 has active disease, discontinuation or tapering of thiopurine and corticosteroids should be decided based on disease severity, and alternative treatments including budesonide, exclusive enteral nutrition, cyclosporine, and anti-TNF should be considered. If the patient is in the third trimester of pregnancy, delivery should also be considered. IBD medication discontinued due to COVID-19 may be restarted after 2 negative SARS-CoV-2 reverse transcriptase polymerase chain reaction tests using nasopharyngeal swabs. ${ }^{79}$

Breastfeeding is not a contraindication in IBD patients during the pandemic, and neonate breastfeeding can be continued if the mother is clinically stable even with COVID-19 infection. ${ }^{80,81}$ Although viral transmission from mother to neonate is possible by close contact and respiratory droplets, WHO encourages breastfeeding because the potential benefit of breastfeeding and skin-to-skin contact between mother and baby outweighs the risk of infection, ${ }^{82}$ but only with strict hygiene including hand washing and wearing face masks during lactation. Bottle-feeding by healthy assistants is an alternative if the mother is unable to cope with the fear of transmission.

In summary, pregnant women with IBD and their partners should take stringent prevention measures, and current IBD medications should be continued in patients with stable disease or in remission if not infected with SARS-CoV-2. When confirmed COVID-19 positive, thiopurine and corticosteroid should be stopped if possible but not 5-ASA, and delivery can be considered to proceed in the third trimester. Anticoagulant prophylaxis should be provided to all hospitalized pregnant IBD patients. Breastfeeding is not an absolute contraindication and can be decided in consultation with the pregnant woman, her family, and the medical staff.

\section{MANAGEMENT OF PATIENTS WITH SUSPECTED} OR CONFIRMED COVID-19

\section{Should IBD treatment be changed in patients with suspected or confirmed COVID-19?}

\section{Statement 10}

In IBD patients with suspected or confirmed COVID-19, stopping and restarting immune-modifying medications should be decided based on COVID-19 severity and IBD activity. 
For IBD patients with suspected or confirmed COVID-19, IBD medication is recommended based on the clinical course and prognosis. However, this is controversial, and a flexible stance is warranted.

According to the SECURE-IBD study, 7\% of IBD patients infected with SARS-CoV-2 progressed to severe COVID-19, defined as ICU admission, ventilator use, and/or death. Old age, 2 or more comorbidities, and systemic corticosteroid use are risk factors for severe COVID-19, and systemic corticosteroid use, in particular, was strongly associated with severe COVID-19 (adjusted odds ratio, 6.9; 95\% CI, 2.3-20.5) and death (adjusted odds ratio, 11.62; 95\% CI, 2.09-64.74). ${ }^{18}$ In a large French cohort study, the risk of hospitalization for COVID-19 was analyzed according to IBD medication. The hazard ratio was 0.94 for immunomodulatory agents, 1.05 for anti-TNF monotherapy, 0.8 for anti-TNF combination therapy, 1.06 for vedolizumab, 1.25 for ustekinumab, and 0.80 for 5-ASA. None of these drugs were significantly associated with the risk of hospitalization. However, in patients on corticosteroids/ budesonide, the hazard ratio of hospitalization for COVID-19 increased to 1.64. There was no significant association between use of corticosteroids/budesonide and ventilator use and death. ${ }^{83}$ IOIBD $^{84}$ and the AGA ${ }^{33}$ recommends that highdose steroids be reduced or changed to budesonide as soon as possible, and budesonide be used for mild disease. However, in patients at risk of adrenal insufficiency due to long-term steroid use, caution is needed when reducing corticosteroid doses.

According to multiple guidelines and recommendations from expert groups, oral or topical 5-ASA is safe and can be maintained for IBD patients with suspected or confirmed COVID-19. ${ }^{64}$ In contrast, thiopurine, methotrexate, biologics, and tofacitinib are recommended to be discontinued immediately, not only in acute COVID-19 but also in individuals suspected of being in close contact with a confirmed COVID-19 individual. ${ }^{33,63,84,85}$ For asymptomatic SARS-CoV-2-infected IBD patients or those who have been in close contact with confirmed COVID-19 cases, these medications should be discontinued, and the patients observed for 10-14 days; the medications can be restarted if there are no symptoms of COVID-19. This is based on infected patients in the general population, in whom COVID-19-related symptoms developed within 14 days of close contact with an infected person or confirmed infection. Among residents of nursing homes, $89 \%$ of asymptomatic patients confirmed positive for the virus developed COVID-19 symptoms within 7 days. ${ }^{35,86}$ Restarting IBD medications in symptomatic COVID-19 patients can be considered if the patient is fever-free for at least 3 days and respiratory symptoms improve,

Table 3. Recommended Therapeutics in Inflammatory Bowel Disease Patients Infected with SARS-CoV-2

\begin{tabular}{|c|c|c|}
\hline Drug & $\begin{array}{l}\text { Exposed patients to SARS-CoV-2 or } \\
\text { SARS-CoV-2 test positive patients } \\
\text { without COVID-19 symptoms }\end{array}$ & $\begin{array}{l}\text { COVID-19 confirmed patient } \\
\text { (symptomatic) }\end{array}$ \\
\hline 5-ASA & Maintain. & Maintain. \\
\hline Corticosteroids & $\begin{array}{l}\text { Use when necessary (e.g., acute exacerbation), } \\
\text { but reduce the dose if possible. } \\
\text { Do not continuously use prednisolone at } 20 \text { mg } \\
\text { or more per day. Consider dose reduction as } \\
\text { soon as possible. }\end{array}$ & $\begin{array}{l}\text { Use when necessary (e.g., acute exacerbation), but reduce } \\
\text { the dose if possible. } \\
\text { Do not continuously use prednisolone at } 20 \mathrm{mg} \text { or more } \\
\text { per day. Consider dose reduction as rapidly as possible. }\end{array}$ \\
\hline $\begin{array}{l}\text { Immunomodulators } \\
\text { (thiopurine/methotrexate) }\end{array}$ & $\begin{array}{l}\text { Withhold for } 10-14 \text { days, and if no symptoms of } \\
\text { COVID-19, restart. }\end{array}$ & $\begin{array}{l}\text { Withhold for at least } 14 \text { days. Restart at least } 3 \text { days after } \\
\text { recovery }{ }^{\mathrm{a}} \text { or negative results on } 2 \text { consecutive PCR tests. }\end{array}$ \\
\hline $\begin{array}{l}\text { Anti-TNF (infliximab, adalimumab, } \\
\text { golimumab) }\end{array}$ & $\begin{array}{l}\text { Withhold for } 10-14 \text { days, and if no symptoms of } \\
\text { COVID-19, restart. }\end{array}$ & $\begin{array}{l}\text { Withhold for at least } 14 \text { days. Restart at least } 3 \text { days after } \\
\text { recovery }{ }^{a} \text { or negative results on } 2 \text { consecutive PCR tests. }\end{array}$ \\
\hline Vedolizumab & $\begin{array}{l}\text { Withhold for } 10-14 \text { days, and if no symptoms of } \\
\text { COVID-19, restart. }\end{array}$ & $\begin{array}{l}\text { Withhold for at least } 14 \text { days. Restart at least } 3 \text { days after } \\
\text { recovery }{ }^{a} \text { or negative results on } 2 \text { consecutive PCR tests. }\end{array}$ \\
\hline Ustekinumab & $\begin{array}{l}\text { Withhold for } 10-14 \text { days, and if no symptoms of } \\
\text { COVID-19, restart. }\end{array}$ & $\begin{array}{l}\text { Withhold for at least } 14 \text { days. Restart at least } 3 \text { days after } \\
\text { recoverya or negative results on } 2 \text { consecutive PCR tests. }\end{array}$ \\
\hline Tofacitinib & $\begin{array}{l}\text { Withhold for } 10-14 \text { days, and if no symptoms of } \\
\text { COVID-19, restart. }\end{array}$ & $\begin{array}{l}\text { Withhold for at least } 14 \text { days. Restart at least } 3 \text { days after } \\
\text { recovery or negative results on } 2 \text { consecutive PCR tests. }\end{array}$ \\
\hline
\end{tabular}

aDefined as no fever and improved respiratory symptoms.

SARS-CoV-2, severe acute respiratory syndrome coronavirus-2; COVID-19, coronavirus disease 2019; 5-ASA, 5-aminosalicylic acid; TNF, tumor necrosis factor; PCR, polymerase chain reaction. 
or if 2 consecutive virus tests are negative. ${ }^{35}$ The recommended medications in IBD patients infected with SARS-CoV-2 are shown in Table 3.

In the clinical setting, discontinuation and resumption of IBD medications should be discussed on a case-by-case basis according to IBD disease activity and the types of medications, referring to the principal recommendations. The IOIBD and the AGA recommend that the treatment plan for IBD patients infected with SARS-CoV-2 be adjusted based on COVID-19 severity and IBD activity. ${ }^{33,84,85}$ For example, if a patient has mild COVID-19 or severe IBD, resuming the discontinued IBD medications earlier would be considered. By contrast, if a patient has severe COVID-19 and mild IBD, resumption of IBD medications should be delayed.

\section{CONCLUSION}

During the COVID-19 pandemic, the care of IBD patients at high risk of immunosuppression is a challenge for medical staff and patients. IBD is not a risk factor for COVID-19, and care should be taken not to exacerbate IBD in patients in remission or a stable state by maintaining their medications, except for corticosteroids. In IBD patients who develop COVID-19, it is necessary to re-evaluate treatments that have been maintained, and whether a drug should be stopped or restarted should be decided based on IBD activity and COVID-19 severity. We hope that this recommendation will enhance the care of patients with IBD and assist in the fight against the COVID-19 pandemic.

\section{ADDITIONAL INFORMATION}

\section{Funding Source}

The authors received no financial support for the research, authorship, and/or publication of this article.

\section{Conflict of Interest}

Myung SJ is an editorial board member of the journal but was not involved in the peer reviewer selection, evaluation, or decision process of this article. No other potential conflicts of interest relevant to this article were reported.

\section{Data Availability Statement}

Not applicable.

\section{Author Contribution}

Conceptualization: Kim SE, Chang JY, Song HJ, Kim DH, Yang YJ, Kim BC, Lee JG, Yang HC, Myung SJ. Data curation: Park YE, Lee YJ. Formal analysis: Choi M. Investigation: Park YE, Lee YJ, Kim SE. Methodology: Park YE, Lee YJ, Kim SE, Choi M. Supervision: Kim SE, Myung SJ. Validation: Choi M, Myung SJ. Visualization: Park YE, Lee YJ. Writing - original draft: Park YE, Lee YJ, Kim SE, Chang JY, Song HJ, Kim DH, Yang YJ, Kim BC, Lee JG, Yang HC. Writing - review \& editing: Park YE, Lee YJ, Kim SE, Chang JY, Song HJ, Kim DH, Yang YJ, Kim BC, Lee JG, Yang HC. Approval of final manuscript: all authors.

\section{ORCID}

Park YE

Lee YJ

Chang JY

Song $\mathrm{HJ}$

$\mathrm{Kim} \mathrm{DH}$

Yang YJ

Kim BC

Lee JG

Yang HC

Choi M

Kim SE

Myung SJ

https://orcid.org/0000-0003-4274-8204 https://orcid.org/0000-0003-1799-0146 https://orcid.org/0000-0002-7951-456X https://orcid.org/0000-0002-2561-555X https://orcid.org/0000-0003-3841-5802 https://orcid.org/0000-0001-6325-1104 https://orcid.org/0000-0003-3164-5824 https://orcid.org/0000-0003-2930-8159 https://orcid.org/0000-0001-9847-5343 https://orcid.org/0000-0002-2424-9965 https://orcid.org/0000-0002-6310-5366 https://orcid.org/0000-0003-0585-4016

\section{REFERENCES}

1. Perlman S. Another decade, another coronavirus. N Engl J Med 2020;382:760-762.

2. Sohrabi C, Alsafi Z, O'Neill N, et al. World Health Organization declares global emergency: a review of the 2019 novel coronavirus (COVID-19). Int J Surg 2020;76:71-76.

3. Bezzio C, Saibeni S, Variola A, et al. Outcomes of COVID-19 in 79 patients with IBD in Italy: an IG-IBD study. Gut 2020;69: 1213-1217.

4. Chen N, Zhou M, Dong X, et al. Epidemiological and clinical characteristics of 99 cases of 2019 novel coronavirus pneumonia in Wuhan, China: a descriptive study. Lancet 2020;395:507513.

5. Nair R, Aggarwal R, Khanna D. Methods of formal consensus in classification/diagnostic criteria and guideline development. Semin Arthritis Rheum 2011;41:95-105.

6. Hong KS, Ko SB, Yu KH, et al. Update of the Korean clinical practice guidelines for endovascular recanalization therapy in patients with acute ischemic stroke. J Stroke 2016;18:102- 
113.

7. Choi CH, Moon W, Kim YS, et al. Second Korean guideline for the management of ulcerative colitis. Korean J Gastroenterol 2017;69:1-28.

8. Park JJ, Yang SK, Ye BD, et al. Second Korean guidelines for the management of Crohn's disease. Korean J Gastroenterol 2017;69:29-54.

9. Kim JM, Cheon JH. Pathogenesis and clinical perspectives of extraintestinal manifestations in inflammatory bowel diseases. Intest Res 2020;18:249-264.

10. Winthrop KL, Melmed GY, Vermeire S, et al. Herpes zoster infection in patients with ulcerative colitis receiving tofacitinib. Inflamm Bowel Dis 2018;24:2258-2265.

11. Pauly MP, Tucker LY, Szpakowski JL, et al. Incidence of hepatitis $B$ virus reactivation and hepatotoxicity in patients receiving long-term treatment with tumor necrosis factor antagonists. Clin Gastroenterol Hepatol 2018;16:1964-1973.

12. Ooi CJ, Hilmi I, Banerjee R, et al. Best practices on immunomodulators and biologic agents for ulcerative colitis and Crohn's disease in Asia. J Gastroenterol Hepatol 2019;34:12961315 .

13. Attauabi M, Poulsen A, Theede K, et al. Prevalence and outcomes of COVID-19 among patients with inflammatory bowel disease: a Danish prospective population-based cohort study. J Crohns Colitis 2021;15:540-550.

14. Derikx LA, Lantinga MA, de Jong DJ, et al. Clinical outcomes of COVID-19 in patients with inflammatory bowel disease: a nationwide cohort study. J Crohns Colitis 2021;15:529-539.

15. Aziz M, Fatima R, Haghbin H, Lee-Smith W, Nawras A. The incidence and outcomes of COVID-19 in IBD patients: a rapid review and meta-analysis. Inflamm Bowel Dis 2020;26:e132el33.

16. Singh S, Khan A, Chowdhry M, Bilal M, Kochhar GS, Clarke K. Risk of severe coronavirus disease 2019 in patients with inflammatory bowel disease in the United States: a multicenter research network study. Gastroenterology 2020;159:15751578.

17. Lukin DJ, Kumar A, Hajifathalian K, et al. Baseline disease activity and steroid therapy stratify risk of COVID-19 in patients with inflammatory bowel disease. Gastroenterology 2020; 159:1541-1544.

18. Brenner EJ, Ungaro RC, Gearry RB, et al. Corticosteroids, but not TNF antagonists, are associated with adverse COVID-19 outcomes in patients with inflammatory bowel diseases: results from an international registry. Gastroenterology 2020;159:481491.
19. Rodríguez-Lago I, Ramírez de la Piscina P, Elorza A, Merino O, Ortiz de Zárate J, Cabriada JL. Characteristics and prognosis of patients with inflammatory bowel disease during the SARSCoV-2 pandemic in the Basque Country (Spain). Gastroenterology 2020;159:781-783.

20. Allocca M, Fiorino G, Zallot C, et al. Incidence and patterns of COVID-19 among inflammatory bowel disease patients from the Nancy and Milan Cohorts. Clin Gastroenterol Hepatol 2020;18:2134-2135.

21. Taxonera C, Sagastagoitia I, Alba C, Mañas N, Olivares D, Rey E. 2019 novel coronavirus disease (COVID-19) in patients with inflammatory bowel diseases. Aliment Pharmacol Ther 2020;52:276-283.

22. Gubatan J, Levitte S, Balabanis T, Patel A, Sharma A, Habtezion A. SARS-CoV-2 testing, prevalence, and predictors of COVID-19 in patients with inflammatory bowel disease in Northern California. Gastroenterology 2020;159:1141-1144.

23. Guan WJ, Ni ZY, Hu Y, et al. Clinical characteristics of coronavirus disease 2019 in China. N Engl J Med 2020;382:17081720.

24. Zhou F, Yu T, Du R, et al. Clinical course and risk factors for mortality of adult inpatients with COVID-19 in Wuhan, China: a retrospective cohort study. Lancet 2020;395:1054-1062.

25. Yang J, Zheng Y, Gou X, et al. Prevalence of comorbidities and its effects in patients infected with SARS-CoV-2: a systematic review and meta-analysis. Int J Infect Dis 2020;94:91-95.

26. Vardavas CI, Nikitara K. COVID-19 and smoking: a systematic review of the evidence. Tob Induc Dis 2020;18:20.

27. Wenham C, Smith J, Morgan R; Gender and COVID-19 Working Group. COVID-19: the gendered impacts of the outbreak. Lancet 2020;395:846-848.

28. Patrì A, Pinchera B, Spirito L, et al. Gastrointestinal tract diseases as a risk factor for SARSCoV2 rectal shedding? An Italian report on 10 COVID-19 patients. Intest Res 2021;19:354356.

29. Barbosa da Luz B, de Oliveira NM, França Dos Santos IW, et al. An overview of the gut side of the SARS-CoV-2 infection. Intest Res 2021;19:379-385.

30. Hoffmann M, Kleine-Weber H, Schroeder S, et al. SARS-CoV-2 cell entry depends on ACE2 and TMPRSS2 and is blocked by a clinically proven protease inhibitor. Cell 2020;181:271-280.

31. Park J, Jeong D, Chung YW, Kim DH, Cheon JH, Ryu JH. Quantitative proteomic analysis of the expression of SARS-CoV-2 receptors in the gut of patients with chronic enterocolitis. Yonsei Med J 2020;61:891-894.

32. Burgueño JF, Reich A, Hazime H, et al. Expression of SARS- 
CoV-2 entry molecules ACE2 and TMPRSS2 in the gut of patients with IBD. Inflamm Bowel Dis 2020;26:797-808.

33. Rubin DT, Feuerstein JD, Wang AY, Cohen RD. AGA clinical practice update on management of inflammatory bowel disease during the COVID-19 pandemic: expert commentary. Gastroenterology 2020;159:350-357.

34. Kennedy NA, Jones GR, Lamb CA, et al. British Society of Gastroenterology guidance for management of inflammatory bowel disease during the COVID-19 pandemic. Gut 2020;69: 984-990.

35. Aysha AA, Rentsch C, Prentice R, et al. Practical management of inflammatory bowel disease patients during the COVID-19 pandemic: expert commentary from the Gastroenterological Society of Australia Inflammatory Bowel Disease faculty. Intern Med J 2020;50:798-804.

36. Ludvigsson JF, Axelrad J, Halfvarson J, et al. Inflammatory bowel disease and risk of severe COVID-19: a nationwide population-based cohort study in Sweden. United European Gastroenterol J 2021;9:177-192.

37. Toruner M, Loftus EV Jr, Harmsen WS, et al. Risk factors for opportunistic infections in patients with inflammatory bowel disease. Gastroenterology 2008;134:929-936.

38. Singh AK, Jena A, Kumar-M P, Jha DK, Sharma V. Clinical presentation of COVID-19 in patients with inflammatory bowel disease: a systematic review and meta-analysis. Intest Res 2021 Jan 18 [Epub]. https://doi.org/10.5217/ir.2020.00108.

39. Tian Y, Rong L, Nian W, He Y. Review article: gastrointestinal features in COVID-19 and the possibility of faecal transmission. Aliment Pharmacol Ther 2020;51:843-851.

40. Redd WD, Zhou JC, Hathorn KE, et al. Prevalence and characteristics of gastrointestinal symptoms in patients with severe acute respiratory syndrome coronavirus 2 infection in the United States: a multicenter cohort study. Gastroenterology 2020;159:765-767.

41. Wang D, Hu B, Hu C, et al. Clinical characteristics of 138 hospitalized patients with 2019 novel coronavirus-infected pneumonia in Wuhan, China. JAMA 2020;323:1061-1069.

42. Han C, Duan C, Zhang S, et al. Digestive symptoms in COVID-19 patients with mild disease severity: clinical presentation, stool viral RNA testing, and outcomes. Am J Gastroenterol 2020;115:916-923.

43. Cheung KS, Hung IF, Chan PP, et al. Gastrointestinal manifestations of SARS-CoV-2 infection and virus load in fecal samples from a Hong Kong cohort: systematic review and metaanalysis. Gastroenterology 2020;159:81-95.

44. Harmer D, Gilbert M, Borman R, Clark KL. Quantitative
mRNA expression profiling of ACE 2, a novel homologue of angiotensin converting enzyme. FEBS Lett 2002;532:107-110.

45. Goyal P, Choi JJ, Pinheiro LC, et al. Clinical characteristics of COVID-19 in New York city. N Engl J Med 2020;382:23722374.

46. Britton GJ, Chen-Liaw A, Cossarini F, et al. Limited intestinal inflammation despite diarrhea, fecal viral RNA and SARSCoV-2-specific IgA in patients with acute COVID-19. Sci Rep 2021;11:13308.

47. Rahier JF, Magro F, Abreu C, et al. Second European evidencebased consensus on the prevention, diagnosis and management of opportunistic infections in inflammatory bowel disease. J Crohns Colitis 2014;8:443-468.

48. Magro F, Rahier JF, Abreu C, et al. Inflammatory bowel disease management during the COVID-19 outbreak: the ten do's and don'ts from the ECCO-COVID Taskforce. J Crohns Colitis 2020;14(14 Suppl 3):S798-S806.

49. Hrusak O, Kalina T, Wolf J, et al. Flash survey on severe acute respiratory syndrome coronavirus-2 infections in paediatric patients on anticancer treatment. Eur J Cancer 2020;132:1116.

50. Bussalino E, De Maria A, Russo R, Paoletti E. Immunosuppressive therapy maintenance in a kidney transplant recipient with SARS-CoV-2 pneumonia: a case report. Am J Transplant 2020;20:1922-1924.

51. D’Antiga L. Coronaviruses and immunosuppressed patients: the facts during the third epidemic. Liver Transpl 2020;26:832834.

52. Blanco JL, Ambrosioni J, Garcia F, et al. COVID-19 in patients with HIV: clinical case series. Lancet HIV 2020;7:e314-e316.

53. Ungaro RC, Brenner EJ, Gearry RB, et al. Effect of IBD medications on COVID-19 outcomes: results from an international registry. Gut 2021;70:725-732.

54. Agrawal M, Brenner EJ, Zhang X, et al. Characteristics and outcomes of IBD patients with COVID-19 on tofacitinib therapy in the SECURE-IBD Registry. Inflamm Bowel Dis 2021; 27:585-589.

55. An P, Ji M, Ren H, et al. Protection of 318 inflammatory bowel disease patients from the outbreak and rapid spread of COVID-19 infection in Wuhan, China. SSRN [Preprint]. 2020 [cited 2021 Jul 28]. https://ssrn.com/abstract=3543590.

56. Ni YN, Chen G, Sun J, Liang BM, Liang ZA. The effect of corticosteroids on mortality of patients with influenza pneumonia: a systematic review and meta-analysis. Crit Care 2019; 23:99.

57. Stockman LJ, Bellamy R, Garner P. SARS: systematic review of 
treatment effects. PLoS Med 2006;3:e343.

58. Lansbury L, Rodrigo C, Leonardi-Bee J, Nguyen-Van-Tam J, Lim WS. Corticosteroids as adjunctive therapy in the treatment of influenza. Cochrane Database Syst Rev 2019;2:CD010406.

59. Arabi YM, Mandourah Y, Al-Hameed F, et al. Corticosteroid therapy for critically ill patients with Middle East respiratory syndrome. Am J Respir Crit Care Med 2018;197:757-767.

60. World Health Organization. Clinical management of severe acute respiratory infection when novel coronavirus (2019$\mathrm{nCoV}$ ) infection is suspected: interim guidance, 28 January 2020 [Internet]. c2000 [cited 2021 Jul 28]. https://apps.who. int/iris/handle/10665/330893.

61. Lim HW, Schuster IP, Rajapakse R, Monzur F, Khan S, Sultan $K$. The impact of corticosteroid use on inpatients with inflammatory bowel disease and positive polymerase chain reaction for Clostridium difficile. Intest Res 2019;17:244-252.

62. Cline JC, Davis SM. Risks of infection or reactivation of tuberculosis associated with chronic corticosteroid therapy. Ann Pharmacother 1997;31:775-776.

63. Ling KL, Hilmi I, Raja Ali RA, et al. Asian Pacific Association of Gastroenterology (APAGE) Inflammatory Bowel Disease (IBD) Working Party guidelines on IBD management during the COVID-19 pandemic. JGH Open 2020;4:320-323.

64. Kim KO, Jang BI. Management of inflammatory bowel disease in the COVID-19 era. Intest Res 2022;20:3-10.

65. Zingone F, Savarino EV. Viral screening before initiation of biologics in patients with inflammatory bowel disease during the COVID-19 outbreak. Lancet Gastroenterol Hepatol 2020;5:525.

66. D’Amico F, Danese S, Peyrin-Biroulet L; ECCO COVID taskforce. Inflammatory bowel disease management during the coronavirus-19 outbreak: a survey from the European Crohn's and Colitis Organization. Gastroenterology 2020;159:14-19.

67. Dotan I, Panaccione R, Kaplan GG, O’Morain C, Lindsay JO, Abreu MT. Best practice guidance for adult infusion centres during the COVID-19 pandemic: report from the COVID-19 International Organization for the Study of IBD [IOIBD] Task Force. J Crohns Colitis 2020;14(14 Suppl 3):S785-S790.

68. Van Assche G, Vermeire S, Ballet V, et al. Switch to adalimumab in patients with Crohn's disease controlled by maintenance infliximab: prospective randomised SWITCH trial. Gut 2012;61:229-234.

69. Heida A, Dijkstra A, Muller Kobold A, et al. Efficacy of home telemonitoring versus conventional follow-up: a randomized controlled trial among teenagers with inflammatory bowel disease. J Crohns Colitis 2018;12:432-441.

70. Lewin S, Lees C, Regueiro M, Hart A, Mahadevan U. Interna- tional Organization for the Study of Inflammatory Bowel Disease: global strategies for telemedicine and inflammatory bowel diseases. J Crohns Colitis 2020;14(14 Suppl 3):S780S784.

71. Silasi M, Cardenas I, Kwon JY, Racicot K, Aldo P, Mor G. Viral infections during pregnancy. Am J Reprod Immunol 2015;73: 199-213.

72. Di Mascio D, Khalil A, Saccone G, et al. Outcome of coronavirus spectrum infections (SARS, MERS, COVID-19) during pregnancy: a systematic review and meta-analysis. Am J Obstet Gynecol MFM 2020;2:100107.

73. Wong SF, Chow KM, Leung TN, et al. Pregnancy and perinatal outcomes of women with severe acute respiratory syndrome. Am J Obstet Gynecol 2004;191:292-297.

74. Jeong SY, Sung SI, Sung JH, et al. MERS-CoV infection in a pregnant woman in Korea. J Korean Med Sci 2017;32:17171720.

75. Meijer WJ, van Noortwijk AG, Bruinse HW, Wensing AM. Influenza virus infection in pregnancy: a review. Acta Obstet Gynecol Scand 2015;94:797-819.

76. Collin J, Byström E, Carnahan A, Ahrne M. Public Health Agency of Sweden's Brief Report: pregnant and postpartum women with severe acute respiratory syndrome coronavirus 2 infection in intensive care in Sweden. Acta Obstet Gynecol Scand 2020;99:819-822.

77. Rosen MH, Axelrad J, Hudesman D, Rubin DT, Chang S. Management of acute severe ulcerative colitis in a pregnant woman with COVID-19 infection: a case report and review of the literature. Inflamm Bowel Dis 2020;26:971-973.

78. Alsheef MA, Alabbad AM, Albassam RA, et al. Pregnancy and venous thromboembolism: risk factors, trends, management, and mortality. Biomed Res Int 2020;2020:4071892.

79. De Lima-Karagiannis A, Juillerat P, Sebastian S, Pedersen N, Bar-Gil Shitrit A, van der Woude CJ. Management of pregnant inflammatory bowel disease patients during the COVID-19 pandemic. J Crohns Colitis 2020;14(14 Suppl 3):S807-S814.

80. Vassilopoulou E, Feketea G, Koumbi L, Mesiari C, Berghea EC, Konstantinou GN. Breastfeeding and COVID-19: from nutrition to immunity. Front Immunol 2021;12:661806.

81. Zhu C, Liu W, Su H, et al. Breastfeeding risk from detectable severe acute respiratory syndrome coronavirus 2 in breastmilk. J Infect 2020;81:452-482.

82. World Health Organization. Breastfeeding and COVID-19: scientific brief, 23 June 2020 [Internet]. c2020 [cited 2021 Jul 28]. https://apps.who.int/iris/handle/10665/332639.

83. Meyer A, Semenzato L, Zureik M, Weill A, Carbonnel F, Dray- 
Spira R. Risk of severe COVID-19 in patients treated with IBD medications: a French nationwide study. Aliment Pharmacol Ther 2021;54:160-166.

84. Siegel CA, Christensen B, Kornbluth A, et al. Guidance for restarting inflammatory bowel disease therapy in patients who withheld immunosuppressant medications during COVID-19. J Crohns Colitis 2020;14(14 Suppl 3):S769-S773.
85. Allez M, Fleshner P, Gearry R, Lakatos PL, Rubin DT. Care of the patient with IBD requiring hospitalisation during the COVID-19 pandemic. J Crohns Colitis 2020;14(14 Suppl 3):S774S779.

86. Arons MM, Hatfield KM, Reddy SC, et al. Presymptomatic SARS-CoV-2 infections and transmission in a skilled nursing facility. N Engl J Med 2020;382:2081-2090. 